\title{
Determinants of standard motorcycle safety helmet usage among child pillion riders
}

\begin{abstract}
The World Health Organization stressed that compliance with the use of safety helmet could significantly reduce the risk of injury by $72 \%$ and the probability of death by $39 \%$. In Malaysia, the enforcement of the safety helmet legislation significantly reduced $30 \%$ of motorcycle crash fatalities in Malaysia. The aim of this study is to explore the use of motorcycle helmets and the determinants of standard helmet usage among child pillion riders. A cross-sectional survey of 200 adult riders accompanied by the child pillion riders aged 6-12 years old from Klang, Selangor, was conducted. The proper use of the helmet among the respondents and the child pillion riders was observed and recorded. A questionnaire was used to assess socio-demographic background and awareness of the use of child safety helmets. The data was analyzed using SPSS version 23 . Only $3 \%$ of child pillion riders use standard child safety helmets, while $37 \%$ wear standard adult motorcycle helmets. Adult riders who were married, female, always wear helmets, have a higher household income and travel a long distance, are more likely to use a standard motorcycle helmet for their child pillion riders. Knowledge on Standard Certification (SIRIM) label and its importance, awareness of the campaign on child safety helmets, police enforcement, understanding the safety of toy/game helmet use have been identified as additional determinants of standard helmet use among child pillion riders. This study recommends prospective studies with continuous road safety educations programs that integrate behavioural change approaches to enhance the use of standard motorcycle helmets among the child pillion riders in Malaysia.
\end{abstract}

Keyword: Motorcycle rider; Children pillion riders; Adults motorcycle helmet; Child motorcycle helmet 